\title{
ACHADOS AUDIOLÓGICOS E LINGUAGEM EM GÊMEAS REGURGITADORAS
}

\section{Audiology and language findings in twins with gastroesophageal reflux}

\author{
Diogo Henrique Lira de Andrade ${ }^{(1)}$, Cristiane Monteiro Pedruzzi ${ }^{(2)}$, Ilka do Amaral Soares ${ }^{(3)}$, \\ Marisa Frasson de Azevedo ${ }^{(4)}$, Elizângela Dias Camboim ${ }^{(5)}$
}

\begin{abstract}
RESUMO
Tema: achados audiológicos e linguagem em gêmeas regurgitadoras. Procedimentos: o estudo consiste no relato dos achados audiológicos e do desenvolvimento da linguagem de duas crianças, irmãs gêmeas regurgitadoras. Para isso, foram realizadas as seguintes etapas: coleta dos dados nos prontuários, relatórios das pacientes e coleta de informações com os familiares. Nos prontuários, além dos achados audiológicos e de linguagem, foi relatado também o tipo de abordagem terapêutica utilizada e os objetivos dos planejamentos diários que nortearam as sessões. Resultados: as crianças apresentaram ausência das emissões otoacústicas evocadas por estímulo transiente e produto de distorção, e potencial evocado auditivo de tronco encefálico via aérea e via óssea com limiar eletrofisiológico em 30 e 35dBNA bilateralmente, tendo sido sugerido no laudo perda auditiva de grau leve. No acompanhamento apresentaram episódios de otite média secretora, confirmada pela avaliação otorrinolaringológica, e curvas timpanométricas do tipo B e C. As crianças iniciaram a terapia fonoaudiológica aos 10 meses de idade. Foram realizadas 32 sessões terapêuticas para o sujeito A.B. e 28 para o sujeito A.E., no período de 11 meses, nas quais as crianças demonstraram evolução, apresentando produções esperadas para a fase linguística do desenvolvimento da linguagem, porém não eram compatíveis com a idade observada na literatura estudada. Conclusão: as duas crianças com refluxo gastroesofágico apresentaram perda condutiva, audição flutuante nos primeiros dois anos de vida e atraso no desenvolvimento da linguagem. Apesar de suas produções apresentarem atraso, foi possível observar significativa evolução das crianças em relação à aquisição de linguagem dentro do processo terapêutico.
\end{abstract}

DESCRITORES: Perda Auditiva; Refluxo Gastroesofágico; Linguagem

(1) Aluna do curso de Graduação em Fonoaudiologia.

(2) Fonoaudióloga e Psicóloga; Professora Auxiliar da Faculdade de Fonoaudiologia de Alagoas da Universidade Estadual de Ciências da Saúde de Alagoas, UNCISAL, Maceió, AL; Especialista em Audiologia Clínica pelo Instituto de Comunicação de Bauru.

(3) Fonoaudióloga; Professora Auxiliar da Faculdade de Fonoaudiologia de Alagoas da Universidade Estadual de Ciências da Saúde de Alagoas, UNICISAL, Maceió, AL; Especialista em Audiologia Clínica pela Universidade Federal de Pernambuco.

(4) Fonoaudióloga; Professora Adjunta IV da Universidade Federal de São Paulo, UNIFESP, São Paulo, SP; Doutora em Distúrbios da Comunicação Humana pela Universidade Federal de São Paulo.

(5) Fonoaudióloga; Professora Auxiliar da Faculdade de Fonoaudiologia de Alagoas da Universidade Estadual de Ciências da Saúde de Alagoas, UNCISAL, Maceió, AL; Especialista em Audiologia Clínica e Equilibriometria pela Universidade Federal de Pernambuco.

Conflito de interesse: inexistente

\section{INTRODUÇÃO}

A detecção da deficiência auditiva deve ser realizada nos primeiros meses de vida. Portanto, os profissionais que intervêm no desenvolvimento infantil devem estar preparados para identificar alterações da audição e encaminhar para avaliação auditiva. $O$ ideal seria que todas as crianças fossem submetidas a uma avaliação audiológica no período neonatal, por meio de programas de triagem auditiva, pois uma surdez não identificada precocemente pode ter consequências devastadoras sobre o desenvolvimento da linguagem da criança ${ }^{1,2}$.

As técnicas mais empregadas para triagem auditiva neonatal são: as emissões otoacústicas evocadas por estímulo transiente (EOAT), o potencial evocado auditivo de tronco encefálico (PEATE). 
Estes dois métodos exploram formas diferentes da reação auditiva e fornecem informações sobre a integridade de vários níveis do sistema auditivo ${ }^{1-3}$.

As EOAT são respostas a um estímulo acústico e dependem de propriedades ativas da cóclea. São constantes no mesmo indivíduo e sua ausência acontece em patologias de orelha interna ou média. No entanto, a resposta desaparece quando os limiares auditivos estiverem acima de 25 dBNA ${ }^{1,2}$.

O PEATE é o registro das respostas elétricas desencadeadas por um estímulo sonoro ao longo da via auditiva. Sua aplicação permite a avaliação da integridade neural das vias auditivas, da sua porção periférica até o tronco encefálico ${ }^{1,3}$.

A técnica da audiometria comportamental (observação das respostas comportamentais mediante um estímulo sonoro) é capaz de avaliar o desenvolvimento auditivo de acordo com a faixa etária e tem sido amplamente empregada em crianças de zero a seis meses de idade ${ }^{4}$.

O Joint Committee on Infant Hearing $(\mathrm{JClH})$ cita alguns indicadores de risco para perda auditiva. São eles: apgar de zero a quatro no primeiro minuto ou zero a seis no quinto minuto; história familiar de deficiência auditiva; ventilação mecânica por mais de 5 dias; infecções congênitas: Sífilis, Toxoplasmose, Rubéola, Citomegalovírus e Herpes (STORCH); peso ao nascimento $(\mathrm{PN})<1500 \mathrm{~g}$; meningite bacteriana; síndromes associadas à deficiência auditiva condutivas ou neuro-sensoriais; hiperbilirrubinemia em um nível que indique exsanguíneo transfusão; anomalias crânio-faciais; medicação ototóxica, incluindo, mas não se limitando aos aminoglicosídeos; UTI neonatal por mais de $48 \mathrm{~h}^{3}$.

A doença do refluxo gastroesofágico (DRGE) também é considerada como uma das etiologias de perdas auditivas. A presença de DRGE mostra associação positiva com recorrência de secreção na orelha média. Embora seja bastante discutida quanto às complicações que acarreta, nos casos em que o diagnóstico for confirmado, atenção especial deve ser dada ao aspecto auditivo, considerando os riscos de secreção na orelha média e as características insidiosas dessa doença, principalmente em lactentes ${ }^{5,6}$. Alterações da função de orelha média podem prejudicar a captação das emissões otoacústicas, e a ausência destas, em lactentes, pode estar associada a discretas alterações timpanométricas ${ }^{7}$.

O refluxo gastroesofágico (RGE) e a otite média (OM) são desordens comuns em crianças novas. Em 1995, a otite média foi considerada a incidência mais elevada, entre todos os problemas médicos, nas crianças menores que cinco anos de idade. Os estudos recentes sugeriram que RGE pode causar a OM, sendo assim, o RGE é um fator de risco para alterações de orelha média. ${ }^{5-8}$.

A otite média persistente, de fato, tem um efeito deletério sobre o desenvolvimento da fala e da linguagem, por causa da perda auditiva flutuante nos primeiros anos de vida; esse estado auditivo-receptivo inconsistente cria problemas para algumas crianças com perda auditiva leve ${ }^{7}$.

Uma perda auditiva de 16 a 30dBNA terá um efeito significativo na comunicação, no aprendizado da linguagem e no avanço educacional. Os sons das vogais são ouvidos claramente, mas as consoantes surdas podem ser perdidas. Crianças com uma perda auditiva de 16 a 30dBNA podem apresentar desatenção, retardo leve da linguagem e problemas leves na fala. Essas crianças com deficiência auditiva ouvem apenas os fonemas sonoros da fala e de maior intensidade. Os monossílabos átonos e os sons da fala menos intensos, como os fonemas plosivos e os fricativos surdos, são inaudíveis ${ }^{7,9}$.

No desenvolvimento da linguagem são relatadas duas fases: a fase pré-verbal, que ocorre quando a criança inicia vocalizações de fonemas, podendo persistir até por volta de dez a doze meses; e a fase verbal, que se inicia quando a criança fala as primeiras palavras isoladas com compreensão ${ }^{10,11}$.

$\mathrm{Na}$ fase pré-linguística a criança inicia o balbucio, imita sons, produz jargão e compreende ordens simples com auxílio de gestos e palavras familiares associadas a ordens simples. A fase linguística é mais extensa, pois ocorre após os 12 meses de idade. Nesta fase, aproximadamente com 18 meses, a criança começa a combinar duas palavras e poderá ter de 30 a 40 elementos em seu vocabulário; conhece algumas partes do corpo; encontra objetos a pedido e apresenta brincadeira simbólica com objetos. Aos vinte e quatro meses tem vocabulário de cerca de 150 palavras, usando combinações de dois ou três elementos, e segue instruções envolvendo dois conceitos verbais. Ocorre também mudança na direção da funcionalidade e no avanço na aquisição do vocabulário e da estrutura sintática. Estudos voltados para a análise dos processos interativos mostram que o desenvolvimento da comunicação pré-verbal pode ser dividido em quatro níveis ${ }^{10}$ são eles:

\section{Nível I - comunicação não intencional - comportamentos reativos}

Corresponde, aproximadamente, aos dois primeiros meses de vida do bebê. Nesta fase, seus comportamentos estão caracterizados por reações reflexas, como movimentação corporal; o bebê olha, mostra interesse pelas pessoas e objetos, vocaliza, 
chora, agarra objetos que são colocados em sua mão, reage a sons e a vozes familiares.

\section{Nível II - Comunicação não - intencional - comportamentos ativos}

Ocorre dos dois aos oito meses de idade. Nesta fase, o bebê se torna cada vez mais ativo, ou seja, cada vez mais capaz de organizar procedimentos para explorar o mundo ao seu redor. As coisas que são vistas despertam o desejo de pegar, as coisas que são pegas também devem ser vistas, ouvidas e sentidas pela boca.

\section{Nível III - Comunicação pré-linguística intencional elementar}

Acontece dos 8 aos 12 meses. É caracterizado pelo aparecimento de condutas comunicativas novas e que revelam a intencionalidade da criança. Busca meios de comunicar alguma coisa para alguém. Pode apontar um objeto que deseja ou ficar olhando alternadamente para o objeto e o adulto que está próximo. Estes comportamentos tendem a serem acompanhados de vocalização.

\section{Nível IV - Comunicação pré-linguística intencional convencional}

Inicia-se a partir dos 12 meses e vai até os 18 meses. corresponde a um desdobramento da fase anterior. O gesto de apontar começa a ser usado sistematicamente, balançar a cabeça para expressar negação, fazer movimento de "chamar" com as mãos, gesto de bater palmas e dar "tchau". Ela pode dizer "papai", quando vê o pai chegando em casa, quando o ouve abrir a porta; ela pode dizer "au au" quando ouve ou vê um cachorro latindo. Comportamento imitativo, nesta fase as crianças querem imitar tudo o que veem: gestos, expressões e palavras.

A última fase do período sensório-motor, a partir dos 18 meses de idade, é marcada pelo surgimento de condutas representativas que revelam o início da função simbólica ou representativa. Nesta fase a criança manifesta condutas comunicativas, na forma de brincar ou manipular os objetos e no modo como realiza as imitações. Desenvolve uma possibilidade de lidar com realidades ausentes simbolizando-as de alguma forma ${ }^{10}$.

A fala é composta por uma cadeia de fonemas que são interdependentes no contexto. Na criança, este conhecimento se torna essencial no desenvolvimento e na especificidade de cada sinal acústico. É preciso que ouça todos os detalhes da fala e da linguagem para que consiga armazenar as informações de cada segmento fonêmico, de cada palavra, de cada sentença que ouve. As inconsistências na mensagem da fala, que podem ser causadas pela flutuação na recepção do sinal auditivo, podem atrasar a aquisição das estruturas das unidades perceptuais da fala ${ }^{11,12}$

Problemas condutivos provocam uma redução na intensidade dos sons que alcançam a cóclea. Os sons são percebidos de forma reduzida, abafados, perdendo sua profundidade, sua riqueza e sua dimensão. Habilidades auditivas como: dificuldades para localizar a fonte sonora e entender a fala em presença de ruído podem apresentar-se alteradas, pois dependem de uma boa qualidade da audição ${ }^{11,12}$.

A primeira justificativa para a identificação precoce das deficiências auditivas está relacionada ao impacto desta na aquisição da linguagem e no desenvolvimento socioemocional. Os três primeiros anos de vida são fundamentais para a aquisição da linguagem e da fala. Estudos em animais mostram que a privação auditiva parcial ou total precoce interfere no desenvolvimento de estruturas neurais, necessárias para a audição. Portanto, crianças com perda auditiva de grau leve passam por uma ruptura similar, ou seja, a falta de "algumas informações" que terão um impacto direto no seu desenvolvimento global ${ }^{12}$.

Em qualquer alteração auditiva se faz necessária a intervenção imediata com terapia fonoaudiológica para estimulação da aquisição e desenvolvimento da linguagem e, dependendo do grau, com adaptação de aparelho de amplificação sonora individual (AASI), para um prognóstico mais favorável. Criança com deficiência auditiva pode apresentar atraso na aquisição das estruturas das unidades perceptuais da fala, ficar excluída da forma de comunicação oral, ser privada de som no período crítico para aquisição de linguagem e, com isso, perder parte da reflexão da realidade que se produz graças à linguagem ${ }^{9}$.

De acordo com a literatura, a ausência de emissões otoacústicas pode estar associada a discretas alterações timpanométricas ${ }^{13,14}$. Sabemos que crianças com refluxo gastroesofágico podem apresentar alterações na orelha média e que esta é uma das causas de perda auditiva, a qual interfere no desenvolvimento da linguagem, mesmo em grau leve, principalmente quando não há intervenções ou diagnóstico precoce. Diante disso, torna-se relevante relatar o desenvolvimento das gêmeas e descrever como elas evoluíram num período considerado crítico para aquisição da linguagem, antes mesmo de fechar o diagnóstico, a fim de sensibilizar os profissionais que atuam na área infantil para que estes se conscientizem da importância do diagnóstico auditivo em crianças com refluxo, como 
também, o encaminhamento para intervenção fonoaudiológica o quanto antes.

Este trabalho tem como objetivo relatar, até os dois anos de idade, todos os achados audiológicos e do desenvolvimento da linguagem de gêmeas com refluxo gastroesofágico.

\section{APRESENTAÇÃO DOS CASOS}

O estudo consiste no relato dos achados audiológicos e do desenvolvimento da linguagem de duas crianças, irmãs gêmeas, até dois anos de idade, nascidas no dia 26/04/2006, com 37 semanas e quatro dias de idade gestacional. A seguir será realizada a caracterização dos sujeitos da pesquisa, sendo estes identificados por siglas que representam as iniciais de seus nomes:

A.E. nasceu adequada para idade gestacional (AIG), com peso ao nascimento de $2.610 \mathrm{~g}$, APGAR: oito no primeiro minuto e nove no quinto, apresentando-se com hipoatividade e hipotermia. Esta última ocasionou o seu encaminhamento para aquecimento em incubadora por aproximadamente 24 horas.

A.B. nasceu pequena para idade gestacional (PIG), com peso ao nascimento de $1.995 \mathrm{~g}$, APGAR: sete no primeiro minuto e nove no quinto, apresentando-se com hipoatividade e hipotermia, o que também fez com que fosse encaminhado para aquecimento em incubadora por aproximadamente 24 horas.

Para a realização do estudo o pesquisador principal realizou as seguintes etapas:

Termo de Consentimento Livre e Esclarecido

Os responsáveis pelas pacientes autorizaram que os dados das crianças fossem utilizados por meio de um consentimento livre e esclarecido, o qual continha informações detalhadas sobre o estudo.

\section{Coleta de dados}

Foi realizada a coleta dos dados nos prontuários e relatórios dos atendimentos fonoaudiológicos das pacientes atendidas em uma Clínica Escola, com sessão terapêutica de 45 minutos, uma vez por semana. Relataram-se os achados audiológicos e de evolução da terapia fonoaudiológica para linguagem no período de 11 meses. A intervenção teve início aos dez meses de idade e os dados foram coletados até os dois anos e um mês. Neste período, foram realizadas 32 sessões com o sujeito A.B. e 28 sessões com o sujeito A.E., segundo evoluções feitas em prontuários.

As gêmeas eram atendidas individualmente pela supervisora, professora da área de audiologia educacional responsável pelo caso, até junho de 2007, com única evolução para os dois atendimentos. A partir de julho de 2007, A. B. começou a intervenção terapêutica com uma estagiária e A.E. manteve-se em atendimento com a supervisora. Com isso, as evoluções passaram a ser realizadas separadamente.

Foram relatados os achados audiológicos com base nas cópias dos exames audiológicos contidos nos prontuários, e o desenvolvimento de linguagem foi relatado a partir das evoluções feitas pelos terapeutas nesses prontuários. Os dados foram coletados em forma de transcrição, respeitando os relatos e anotações realizadas pelo terapeuta responsável pelo caso.

Foram também coletados o tipo de abordagem terapêutica utilizada e os objetivos dos planejamentos diários que nortearam as sessões, bem como as terapeutas que realizaram os atendimentos.

\section{Informações dos familiares}

Foram colhidas informações com os familiares, sobre as medicações, doenças e intervenções médicas às quais as crianças foram submetidas ao longo dos dois primeiros anos de idade, para complementação do estudo.

O protocolo desta pesquisa está baseado na legislação pertinente, resolução № 196/96, do Conselho Nacional de Saúde, do Ministério da Saúde, para estudos com seres humanos. Esta pesquisa foi aprovada pelo Comitê de Ética em Pesquisa da Universidade Estadual de Ciências da Saúde de Alagoas - UNCISAL, sob o protocolo número 868/2008.

Os dados obtidos com os familiares e anamnese serão descritos e o relato dos achados audiológicos e do desenvolvimento de linguagem serão apresentados em forma de tabela, respectivamente.

\section{RESULTADOS}

As gêmeas nasceram em um hospital particular da cidade de Maceió, submeteram-se a triagem auditiva neonatal numa clínica também particular, na qual falharam nesse teste. Elas apresentaram nos exames audiológicos hipótese diagnóstica de perda auditiva condutiva de grau leve e atualmente estão em terapia Fonoaudiológica em uma clínica-escola.

A abordagem terapêutica utilizada com as gêmeas foi o Oralismo, desde o início da intervenção Fonoaudiológica até o período final do relato do caso. Os planejamentos diários tinham como objetivo geral: proporcionar ambiente favorável à aquisição de linguagem e sua constituição enquanto sujeito pleno. Os objetivos específicos foram: proporcionar experiência simbólica com diversos 
objetos num contexto lúdico; desenvolver a compreensão e expressão oral da linguagem; desenvolver habilidades auditivas e; estimular movimentos orofaciais.

Segundo informações colhidas com os familiares, as crianças iniciaram o uso de antibióticos aos quatro meses de vida, pois apresentaram quadro de pneumonia. Em setembro de 2007 e março de 2008, as gêmeas voltaram a apresentar pneumonia e nesse mês de setembro, A.E. necessitou ser internada por cinco dias. Os pais referiram em anamnese que em uma consulta ao médico otorrinolaringologista, A. E. apresentou rolha de cera no meato acústico externo. Foram os pais orientados, nessa consulta, quanto ao uso de antibióticos, pois as crianças também apresentavam otite média aguda. $O$ medicamento frequentemente usado pelas gêmeas foi o antibiótico Sigmoclave, cujo princípio ativo ou fármaco é: amoxicilina e ácido clavulânico, usado em casos de pneumonia e otite média aguda. Os pais referiram ainda que desde o nascimento elas apresentam refluxo gastroesofágico, por isso fazem uso dos medicamentos Label, cujo princípio ativo ou fármaco é cloridrato de ranitidina, e Motilium, cujo princípio ativo ou fármaco é domperidona. Receberam alta dos medicamentos para refluxo gastroesofágico com um ano de idade e, após três meses, tiveram recidiva do refluxo gastroesofágico voltando a tomar Label, de que fazem uso até os dias atuais. Referiram ainda regurgitações frequentes, principalmente após as mamadas, até aproximadamente 18 meses.

Os dados de evolução do prontuário serão apresentados em uma mesma tabela para os dois sujeitos (Tabela 1).

\section{DISCUSSÃO}

Como foi relatada anteriormente, as gêmeas realizaram triagem auditiva neonatal, iniciando a bateria de exames audiológicos aos três meses e 22 dias de nascidas, em uma clínica particular na cidade de Maceió. Elas apresentaram nos exames audiológicos respostas sugestivas de perda auditiva condutiva ou perda auditiva sensorial de grau leve, pois apresentaram ausência de respostas nas emissões otoacústicas evocadas por estímulo transiente (EOAT) e produto de distorção (EOA PD), bilateralmente. Com isso, foi solicitado PEATE via aérea para fins de diagnóstico: A.B. apresenta limiar eletrofisiológico em 35dBNA bilateralmente e A.E. limiar eletrofisiológico em 30dBNA bilateralmente, confirmados no PEATE por via óssea, realizado após 4 meses. $\mathrm{Na}$ imitância acústica, A.B. apresentou timpanogramas do tipo $B$ em ambas as

Tabela 1 - Achados audiológicos: A. B.

\begin{tabular}{|c|c|c|}
\hline Exames & Data & Resultados \\
\hline EOAT & 04/08/2006 & Ausentes bilateralmente \\
\hline Avaliação comportamental & $04 / 08 / 2006$ & $\begin{array}{l}\text { Reagiu aos instrumentos de leve intensidade } \\
\text { (aproximadamente } 38 \mathrm{dBNA} \text { ) e apresentou RCP para o agogô. }\end{array}$ \\
\hline Imitanciometria & $07 / 08 / 2006$ & $\begin{array}{l}\text { Timpanogramas do tipo "A", com presença dos reflexos } \\
\text { contralaterais bilateralmente. }\end{array}$ \\
\hline EOA PD & $15 / 08 / 2006$ & Ausentes bilateralmente \\
\hline PEATE por via aérea & $17 / 08 / 2006$ & Limiar eletrofisiológico em 35dBNA bilateralmente. \\
\hline EOAT / EOA PD & $29 / 11 / 2006$ & Ausentes bilateralmente \\
\hline Imitanciometria & $29 / 11 / 2006$ & Timpanogramas do tipo "B" \\
\hline PEATE por via óssea & $10 / 01 / 2007$ & Limiar eletrofisiológico em 35dBNA bilateralmente. \\
\hline Avaliação comportamental & $10 / 01 / 2007$ & $\begin{array}{l}\text { Localização da fonte sonora, em intensidades } \\
\text { moderada/suave, em todas as direções de forma consistente } \\
\text { e imediata, sendo indiretamente acima da cabeça. }\end{array}$ \\
\hline Imitanciometria & 03/08/2007 & $\begin{array}{l}\text { Timpanogramas tipo "B" com ausência dos reflexos contra e } \\
\text { ipsilaterais bilateralmente. }\end{array}$ \\
\hline Imitanciometria & $05 / 09 / 2007$ & $\begin{array}{l}\text { Timpanogramas tipo "C" com presença do reflexo } \\
\text { contralateral bilateralmente. }\end{array}$ \\
\hline Imitanciometria & $13 / 11 / 2007$ & $\begin{array}{l}\text { Timpanogramas tipo "B" com ausência dos reflexos } \\
\text { contralaterais e ipsilaterais bilateralmente. }\end{array}$ \\
\hline Imitanciometria & $23 / 01 / 2008$ & $\begin{array}{l}\text { Timpanogramas tipo "A" com presença do reflexo } \\
\text { contralateral bilateralmente. }\end{array}$ \\
\hline
\end{tabular}


Tabela 2 - Achados audiológicos: A. E.

\begin{tabular}{|c|c|c|}
\hline Exames & Data & Resultados \\
\hline EOAT & $04 / 08 / 2006$ & $\begin{array}{l}\text { Ausentes na OD e presente para as frequências até } 2000 \mathrm{~Hz} \\
\text { na OE. }\end{array}$ \\
\hline Avaliação comportamental & 04/08/2006 & $\begin{array}{l}\text { Reagiu aos instrumentos de leve intensidade } \\
\text { (aproximadamente } 38 \mathrm{dBNA} \text { ) e apresentou RCP para o agogô. }\end{array}$ \\
\hline Imitanciometria & 07/08/2006 & $\begin{array}{l}\text { Timpanogramas do tipo "A" com presença dos reflexos } \\
\text { contralaterais bilateralmente. }\end{array}$ \\
\hline EOA PD & $15 / 08 / 2006$ & Ausentes na OD e presente apenas em $4000 \mathrm{~Hz}$ na OE. \\
\hline PEATE por via aérea & $17 / 08 / 2006$ & Limiar eletrofisiológico em 30dBNA bilateralmente. \\
\hline EOAT / EOA PD & $29 / 11 / 2006$ & Ausente bilateralmente \\
\hline Imitanciometria & $29 / 11 / 2006$ & $\begin{array}{l}\text { Timpanogramas do tipo "B" na orelha esquerda e "C" na } \\
\text { orelha direita. }\end{array}$ \\
\hline PEATE por via óssea & $10 / 01 / 2007$ & Limiar eletrofisiológico em 30dBNA bilateralmente \\
\hline Avaliação comportamental & $10 / 01 / 2007$ & $\begin{array}{l}\text { Respostas de localização da fonte sonora, em intensidades } \\
\text { moderada/suave em todas as direções de forma consistente e } \\
\text { imediata, sendo indiretamente acima da cabeça. }\end{array}$ \\
\hline Imitanciometria & 03/08/2007 & $\begin{array}{l}\text { Timpanogramas tipo "B" na orelha direita e tipo "C" na orelha } \\
\text { esquerda com ausência dos reflexos contralaterais e } \\
\text { ipsilaterais bilateralmente. }\end{array}$ \\
\hline Imitanciometria & 05/09/2007 & $\begin{array}{l}\text { Timpanogramas tipo "C" com presença dos reflexos } \\
\text { contralaterais bilateral. }\end{array}$ \\
\hline Imitanciometria & $13 / 11 / 2007$ & $\begin{array}{l}\text { Timpanogramas tipo "B" com ausência dos reflexos } \\
\text { contralaterais e ipsilaterais bilateralmente. }\end{array}$ \\
\hline Imitanciometria & $23 / 11 / 2007$ & $\begin{array}{l}\text { Timpanogramas tipo "C" na orelha direita e tipo "A" na orelha } \\
\text { esquerda com presença dos reflexos contralaterais bilateral. }\end{array}$ \\
\hline
\end{tabular}

orelhas e A.E. apresentou Timpanogramas do tipo "B" na orelha esquerda e "C" na orelha direita.

$\mathrm{Na}$ avaliação comportamental, ambas reagiram aos instrumentos de leve intensidade (aproximadamente $38 \mathrm{dBNA}$ ), porém com respostas atrasadas para a faixa etária, caracterizando um atraso do desenvolvimento auditivo. Apresentaram RCP (Reflexo Cócleo Palpebral) para o agogô. A literatura afirma que o RCP ocorre em $100 \%$ das crianças com audição normal e sua ausência é indicativa de perda auditiva bilateral, condutiva ou alteração central ${ }^{4}$.

As EOA são registráveis na quase totalidade das orelhas com limiares auditivos de até $25 \mathrm{dBNA}$. Sua ausência pode estar associada a discretas alterações timpanométricas ${ }^{1,2}$.

Com o PEATE é possível usar as medidas para fazer inferências sobre a sensitividade auditiva baseada na presença de respostas a estímulos acústicos apresentados em várias intensidades. $\mathrm{O}$ padrão de normalidade para o limiar eletrofisiológico indica valores em torno de 25 dBNAn ${ }^{1}$.

Em relação aos achados da imitância acústica, a literatura estudada determina que existem três tipos fundamentais de curvas timpanométricas conforme a afecção encontrada na orelha média. A curva tipo $A$, encontrada em indivíduos normais, a curva tipo $B$, encontrada em paciente portador de otite média secretora, ou seja, com líquido na orelha média, e a curva tipo $\mathrm{C}$, encontrada em paciente portador de mau funcionamento tubário ${ }^{13,14}$.

A doença do refluxo gastroesofágico (DRGE) também é considerada como etiologia de perdas auditivas e uma das principais afecções de orelha média. A presença de DRGE mostra associação positiva entre ele e as otites médias recorrentes, que, por sua vez, apresentam impacto na aquisição da linguagem pelas crianças ${ }^{5-8}$.

O tratamento adequado das otites médias nos três primeiros anos de vida é importantíssimo, pois essa é a fase de maior desenvolvimento, considerada período crítico para aquisição de linguagem ${ }^{9}$.

Segundo informações colhidas com os pais das gêmeas, as crianças apresentam refluxo gastroesofágico desde que nasceram, por isso fazem uso dos medicamentos Label e Motilium. Os familiares foram orientados ao uso de antibióticos devido à constatação de otite média e episódio de pneumonia.

Os aminoglicosídeos representam 90\% dos agentes ototóxicos e as alterações auditivas com 


\begin{tabular}{|c|c|}
\hline $\begin{array}{l}\text { Mês de terapia e faixa } \\
\text { etária dos sujeitos da } \\
\text { pesquisa }\end{array}$ & Dados de evolução terapêutica dos sujeitos da pesquisa \\
\hline $\begin{array}{l}\text { No mês de março de } 2007 . \\
10 \text { a } 11 \text { meses de idade. }\end{array}$ & $\begin{array}{l}\text { Reações aos instrumentos musicais e vocalizações durante a brincadeira. } \\
\text { Essas vocalizações não eram dirigidas a nenhum objeto ou pessoa específica. }\end{array}$ \\
\hline $\begin{array}{l}\text { No mês de abril de } 2007 . \\
11 \text { a } 12 \text { meses de idade. }\end{array}$ & $\begin{array}{l}\text { Neste período elas aprenderam a bater palmas, a partir de ordens simples: } \\
\text { "bate palma!". }\end{array}$ \\
\hline $\begin{array}{l}\text { Mês de maio de } 2007 . \\
12 \text { a } 13 \text { meses de idade. }\end{array}$ & $\begin{array}{l}\text { Elas iniciaram a realização de todas estas ações (beijo, dar tchau) e } \\
\text { vocalizações ( barulho do carro, mama) de acordo com a ordem auditiva. }\end{array}$ \\
\hline $\begin{array}{l}\text { Mês de junho de } 2007 . \\
\text { Um ano e dois meses. }\end{array}$ & $\begin{array}{l}\text { Executaram o gesto, indicar 1, quando perguntadas sobre a idade e } \\
\text { apresentaram vocalização do "a" } \rightarrow \text { alô. }\end{array}$ \\
\hline $\begin{array}{l}\text { Mês de julho de } 2007 . \\
\text { Um ano e três meses. }\end{array}$ & $\begin{array}{l}\text { A.B. comunica-se com "não", balançando a cabeça, quando não quer algo. } \\
\text { A.E. faz emissão de "mama" } \rightarrow \text { mamãe. }\end{array}$ \\
\hline $\begin{array}{l}\text { Mês de agosto de } 2007 . \\
\text { Um ano e quatro meses. }\end{array}$ & $\begin{array}{l}\text { Reconhecem e realizam ordens simples como: pegar a mochila, pega o } \\
\text { sapato, vai buscar o au au, realiza sopro com a boca. Emite "au au" } \\
\rightarrow \text { cachorro. }\end{array}$ \\
\hline $\begin{array}{l}\text { Mês de setembro de } 2007 . \\
\text { Um ano e cinco meses. }\end{array}$ & $\begin{array}{l}\text { A.B. vocalizou "ó" } \rightarrow \text { bola, "a" } \rightarrow \text { tchau. Sempre que desejava algum objeto } \\
\text { apontava e falava "um". Demonstrou compreender as ordens simples: senta, } \\
\text { guarda o brinquedo no armário, abra e feche a porta. A.E. não compareceu ao } \\
\text { atendimento. }\end{array}$ \\
\hline $\begin{array}{l}\text { Mês de outubro de } 2007 . \\
\text { Um ano e seis meses. }\end{array}$ & $\begin{array}{l}\text { O quadro da doença se agravou com pneumonia e A.B. necessitou de } \\
\text { internação, com isso param a terapia e a escola. No entanto, ainda foi possível } \\
\text { observar emissão de "mama" } \rightarrow \text { mamãe, "papa" } \rightarrow \text { papai, "au" } \rightarrow \text { cachorro, } \\
\text { "mau" } \rightarrow \text { miau, "aku" } \rightarrow \text { água. Elas já demonstram, a partir da estimulação, a } \\
\text { relação nome e cor. Identificam a boneca, panelinha e outros brinquedos, } \\
\text { animais e partes do corpo, de acordo com a pista auditiva. }\end{array}$ \\
\hline $\begin{array}{l}\text { Mês de novembro de } 2007 \text {. } \\
\text { Um ano e sete meses. }\end{array}$ & $\begin{array}{l}\text { A.E. fez "não" com movimentos de cabeça, "mama" } \rightarrow \text { mamãe, "auau" } \rightarrow \\
\text { cachorro, "aaa" para guardar e cantar. Identificou as partes do corpo: olho, } \\
\text { boca, barriga, pé e mão. Além de obedecer às ordens: guardar, sentar e abrir } \\
\text { a porta. A.B. não apresenta grande dificuldade para realizar as ordens } \\
\text { quando solicitada, simbolizou o preparo da comida e alimentou a boneca, nina } \\
\text { a boneca enquanto a estagiária canta música de ninar e vocalizou "la" } \rightarrow \text { bola, } \\
\text { "auau" } \rightarrow \text { cachorro. }\end{array}$ \\
\hline $\begin{array}{l}\text { Mês de dezembro de } 2007 . \\
\text { Um ano e oito meses. }\end{array}$ & $\begin{array}{l}\text { A.E. vocaliza "a" } \rightarrow \text { alô, dá tchau e faz com a mão "vem cá"; com peças de } \\
\text { encaixe a paciente atende a ordem e seleciona por cores, nomeia "papa" } \rightarrow \\
\text { pato. A.B. falou "mama" } \rightarrow \text { mamãe, demonstra boa compreensão de ordens: } \\
\text { colocar, tirar, pegar e guardar. Vocalizou "miau" } \rightarrow \text { gato. }\end{array}$ \\
\hline $\begin{array}{l}\text { Mês de fevereiro de } 2008 . \\
\text { Um ano e } 10 \text { meses. }\end{array}$ & $\begin{array}{l}\text { A.E. compreende a nomeação de vários objetos, como: bola, carro, bebê. No } \\
\text { final das sessões ela chama "papa" } \rightarrow \text { papai e "mama" } \rightarrow \text { mamãe. A.B. } \\
\text { chamou "nenê } \rightarrow \text { criança, "auau" } \rightarrow \text { cachorro, "aua" } \rightarrow \text { água e vocalizou } \\
\text { "ooó" } \rightarrow \text { bola. }\end{array}$ \\
\hline $\begin{array}{l}\text { Mês de março de } 2008 . \\
\text { Um ano e } 11 \text { meses. }\end{array}$ & Não compareceram ao atendimento por motivo de doença. \\
\hline $\begin{array}{l}\text { Mês de abril de } 2008 . \\
\text { Dois anos. }\end{array}$ & Não compareceram ao atendimento por motivo de doença. \\
\hline $\begin{array}{l}\text { Mês de maio de } 2008 . \\
\text { Dois anos e um mês. }\end{array}$ & $\begin{array}{l}\text { Em atividade de montagem de brinquedos de encaixe, A.B. falou "bou" } \rightarrow \\
\text { acabou, nenê e fez imitação da palavra mingau, } \rightarrow \text { "gau". Para gato } \rightarrow \text { "miau" } \\
\text { e piu-piu } \rightarrow \text { "pi-pi". Falou também "mama", "pai" e "pê" } \rightarrow \text { Pedro. Fez } \\
\text { interjeição de "humm..." enquanto simboliza comer e onomatopéia de "chhh", } \\
\text { simbolizando o banho da boneca. Além de pedir peças do jogo de montar, "dá } \\
\text { mais". Demonstra boa compreensão para ordens simples e poucos } \\
\text { complexas, realizando a ordem: pega o livro da mesa e coloca na pia. A.B. } \\
\text { reconheceu as figuras do carro, falando "bibi", boneca } \rightarrow \text { "nenê, cachorro } \rightarrow \\
\text { uôu - uôu e gato } \rightarrow \text { "iáo". } \\
\text { No prontuário da A.E. não apresenta evolução para este mês. }\end{array}$ \\
\hline
\end{tabular}


esta origem constituem $2 \%$ do total das deficiências auditivas neurossensoriais. A administração destes ototóxicos é um dos indicadores de risco e podem levar a perda auditiva permanente ${ }^{3}$. Vale a pena ressaltar que as crianças não apresentaram outros indicadores de risco ao nascimento.

Mesmo com limiares eletrofisiológicos por via aérea e via óssea iguais, foi possível diagnosticar perda auditiva condutiva de grau leve nos dois primeiros anos das gêmeas estudadas. A justificativa para o PEATE por via óssea (VO) ter como resultado os mesmo valores de via aérea é que a avaliação por VO só foi realizada 4 meses após a VA, e assim poderia ocorrer uma mudança da alteração, uma vez que se trata de um tipo de alteração flutuante. Muitas crianças com otite média têm limiares auditivos normais. As principais consequências das otites médias e da perda auditiva sobre a linguagem em crianças são erros fonéticos e de articulação da fala, bem como dificuldade para compreensão da leitura ${ }^{\text {? }}$.

Como o desenvolvimento da linguagem envolve múltiplos processos, sua evolução está na dependência destas interações das quais fatores biológicos, sociais e psicológicos fazem parte. A literatura tem apontado a possibilidade de ocorrência de atraso na aquisição e desenvolvimento de linguagem em gêmeos, bem como atraso do desenvolvimento neuropsicomotor ${ }^{15-20}$. AB. apresentou atraso do desenvolvimento neuropsicomotor, necessitando de fisioterapia aos 3 meses para sustentação de cabeça. AE. demorou a andar, apresentando marcha na ponta dos pés até os dias atuais.

A terapia fonoaudiológica teve início como prevenção secundária, no intuito de minimizar as consequências que a perda auditiva poderia trazer para o desenvolvimento da linguagem das crianças. Estas ingressaram na clínica fonoaudiológica aos 10 meses de idade, mesmo antes de concluir o diagnóstico da perda auditiva.

Pode-se observar que de 10 a 11 meses de idade, período em que iniciaram a terapia fonoaudiológica, as gêmeas apresentaram reações aos instrumentos musicais e vocalizações durante a brincadeira, no entanto, essas vocalizações não eram dirigidas a nenhum objeto ou pessoa específica. Dos 12 aos 13 meses, as crianças começaram a apresentar vocalizações de acordo com ordem auditiva.

A literatura aponta que na comunicação pré-linguística intencional elementar, que se inicia a partir dos 8 meses e vai até 1 ano de idade, é observado o início da intencionalidade, em que a criança deve dirigir atitudes comunicativas aos outros, procurando dar início à interação ou respondendo às tentativas dos outros. Esses comportamentos tendem, muitas vezes, a serem acompanhados de vocalização na medida em que a criança também vai compreendendo suas possibilidades de utilizar recursos vocais na comunicação e verifica os efeitos que elas produzem em suas tentativas de comunicar ${ }^{10}$.

Observou-se que as gêmeas, no período de 12 a 13 meses de idade, começaram a dar funcionalidade às palavras: tchau, beijo, dar, barulho de carro. Com um ano e três meses comunicam-se com "não", balançando a cabeça, um ano e quatro meses começaram a dizer "au au" $\rightarrow$ à cachorro, e com um ano e seis meses observou-se, na evolução das pacientes, que elas falavam "papa' $\rightarrow$ à papai, "au" $\rightarrow$ à cachorro, "mau" $\rightarrow$ à miau e "aku" $\rightarrow$ à água. Com isso, as gêmeas apresentaram produções esperadas para o nível da Comunicação pré-linguística intencional convencional, que corresponde ao início da quinta fase sensório-motora e vai até os 18 meses, como afirma a literatura ${ }^{10}$.

Aos 18 meses, as crianças começaram a identificar as partes do corpo, de acordo com a pista auditiva. Aos 19 meses apresentaram brincadeiras simbólicas como: preparar a comida e alimentar a boneca. Aos dois anos e um mês, A.B. começa a combinar duas palavras, pedir peças do jogo de montar, dizendo "dá mais". A literatura afirma que aos 18 meses a criança já começa a combinar duas palavras ${ }^{10}$. Pode-se observar assim que A.B. demonstra produções para a fase lingual, no entanto, fora da faixa etária esperada.

Foi observado no período de terapia que as gêmeas apresentaram criptofasia, fenômeno comum na comunicação de gêmeos, definido como linguagem verdadeira capaz de ser analisada, em forma de sinais íntimos verbais e não verbais com significados compartilhados pelas irmãs desde o período pré-verbal, época na qual o significado advém do reconhecimento e intercâmbios compartilhados e repetidos ${ }^{17-20}$.

Aos dois anos e um mês, A.B. começou a demonstrar a função simbólica ou representativa, pois ela realizava interjeição de "humm" enquanto simbolizava comer e onomatopeia de "chhh" simbolizando o banho da boneca. De acordo com a literatura, a capacidade da função simbólica ou representativa manifesta-se nas condutas comunicativas, na forma como a criança brinca ou manipula os objetos e no modo como passa a realizar as imitações ${ }^{10}$.

Observou-se que as gêmeas, com um ano e quatro meses, demonstraram boa compreensão para ordens simples realizando as ordens de colocar, tirar, pegar e guardar. Aos dois anos e um mês, A.B. demonstrou boa compreensão de ordens pouco complexas: pegar o livro da mesa e colocar na pia. 
É importante ressaltar que nos últimos meses de terapia, relatados neste estudo, as crianças apresentaram timpanogramas normais e ausência do refluxo gastroesofágico, já que estavam em tratamento medicamentoso.

Quanto às habilidades linguísticas, o ganho observado refere-se à intenção comunicativa e compreensão, apresentando comportamentos dirigidos e atendendo a ordens simples. Embora este ganho seja evidente, o desempenho observado está abaixo do esperado para faixa etária. Em gêmeos os estudos têm mostrado que há uma tendência ao atraso no desenvolvimento de linguagem ${ }^{15-20}$.

\section{CONCLUSÃO}

As duas crianças com refluxo gastroesofágico apresentaram perda condutiva de grau leve, audição flutuante nos primeiros dois anos de vida e atraso no desenvolvimento da linguagem. Apesar de suas produções apresentarem atraso, foi possível observar significativa evolução das crianças em relação à aquisição de linguagem dentro do processo terapêutico.

\begin{abstract}
Background: audiological findings and language in regurgitating twin. Procedures: the study consists of the report concerning the Audiology findings and the speech development in regurgitating twin sisters. The following steps were accomplished for this study: gathering data in medical registers, patient medical reports and gathering family history. In the data medical registers, beyond the Audiology speech findings, we also found a boarding type of used therapeutic approach and the daily objective planning that guided the sessions. Results: children showed absence of otoacoustic emissions caused by transient stimulation, distortion product, and evoked hearing potential of the brain stem by air and by bone conduction with bilaterally electrophysiological threshold in 30 and 35dBNA, and a light degree hearing loss was suggested in the findings. In this follow-up, they had episodes of secretary otitis media, confirmed by the otolaryngology evaluation and tympanometric curves as for type $B$ and C. Children initiated the speech therapy with ten-months age. Thirty-two therapeutical sessions were accomplished for subject A.B., 28 for subject A.E., in a period of eleven months, in which the children demonstrated improvements as for the language phase of the speech development, however they were not compatible with the age observed in studied literature. Conclusion: the two children with gastroesophageal reflux showed conductive loss, floating hearing in the first two years of life and delay in speech development. Although their productions show delay, it was possible to observe significant improvement of the children in relation to the therapeutical speech process.
\end{abstract}

KEYWORDS: Hearing Loss; Gastroesophageal Reflux; Language

\section{REFERÊNCIAS}

1. Azevedo MF. Emissões otoacústicas. In: Figueiredo MS. Conhecimentos essenciais para entender bem as Emissões Otoacústicas e BERA. São José dos Campos. Pulso; 2003. p. 35-83.

2. Durante AS, Carvalho RMM, Costa F, Soares JC. Características das emissões otoacústicas por transientes em programa de triagem auditiva neonatal. Pró-Fono. 2005; 17(2):133-40.

3. Joint Committee on Infant Hearing (JCIH). Year 2007 Position statement: principles for early hearing detection and intervention programs. Pediatrics. 2007; 120(4):898-921.
4. Pinheiro MMC, Azevedo MF, Vieira MM, Gomes $M$. Crianças nascidas pré-termo: comparação entre o diagnóstico do desenvolvimento auditivo com o diagnóstico neurológico. Fono Atual. 2004; 7:32-42.

5. Lieu JEC, Muthappan PG, Uppaluri R. Association of reflux with otitis media in children. Otolaryngol Head Neck Surg. 2005; 133(3):357-61.

6. Crapko M, Kerschner JE, Syring M, Johnston $\mathrm{N}$. Role of extra-esophageal reflux in chronic otitis media with effusion. Laryngoscope. 2007; 117(8):1419-23.

7. Saes SO, Goldberg TL, Montovani JC. Secreção na orelha média em lactentes: ocorrência, recorrência e aspectos relacionados. J Pediatr. 2005; 81(2):133-8. 
8. Costa AJF, Silva GAP, Gouveia PAC, Pereira Filho EM. Prevalência de refluxo gastroesofágico patológico em lactentes regurgitadores. J Pediatr. 2004; 80(4):291-5.

9. Santana AP. Idade crítica para aquisição da linguagem. Dist Comun. 2004; 16(3):343-54.

10. Zorzi JL. Alterações da linguagem infantil: considerações sobre desenvolvimento, avaliação e diagnóstico. In: Lopes Filho O. Tratado de fonoaudiologia. São Paulo: Tecmedd; 2005. p. 615-35.

11. Kaminski JM, Tochetto TM, Mota HB. Maturação da função auditiva e desenvolvimento de linguagem. Rev Soc Bras Fonoaudiol. 2006; 11(1):17-21.

12. Santos JN, Lemos SMA, Rates SPM, Lamounier JA. Habilidades auditivas e desenvolvimento de linguagem em crianças. Pró-Fono. 2008; 20(4):255-60.

13. Silva KAL, Novaes BACC, Lewis DR, Carvallo RMM. Achados timpanométricos em neonatos com emissões otoacústicas presentes: medidas e interpretações. Rev Bras Otorrinolaringol. 2007;73(5):633-9.

14. Linares AE, Carvallo RMM. Medidas imitanciométricas em crianças com ausência de emissões otoacústicas. Rev Bras Otorrinolaringol. 2008; 74(3):410-6.
15. Weber DE, Vares MA, Mota HB, Keske-Soares M. Desenvolvimento do sistema fonológico de gêmeos monozigóticos com desvio fonológico: correlação a fatores genéticos e ambientais. Rev CEFAC. 2007; 9(1):32-9. dx.doi.org/ S1516-18462007000100005

16. Ferreira AT, Silva MMA, Silva L, Merighi LBM, Miranda AM, De-Vitto LPM, et al. Desempenho comunicativo em trigêmeos prematuros. Rev. CEFAC. São Paulo. 2008; 10(1):15-21. dx.doi.org/ S1516-18462008000100003

17. Leite RA, Stivanin L, Oliveira CCC, Rondina C, Matas CG, Scheuer Cl. Funcionamento da via auditiva e da linguagem em gêmeas monozigóticas com características de mutismo seletivo. Rev Neuroci. 2005; 13(2):74-9.

18. Campos CF, Pádua ACP, Cruz MS, Hage SRV. Alterações de linguagem em gêmeos: relato de caso. Salusvita. 2004; 23(3):513-30.

19. Sutcliffe AG, Derom C. Follow-up of twins: health, behaviour, speech, language outcomes and implications for parents. Early Hum Dev. 2006; 82(6):379-86.

20. Thorpe $K$. Twin children's language development. Early Hum Dev. 2006; 82(6):387-95.

RECEBIDO EM: 21/07/2008

ACEITO EM: 17/06/2009

Endereço para correspondência:

Elizângela Dias Camboim

Rua Cel. Alcides de Barros Ferreira, 26/301

Maceió - AL

CEP: $57036-480$

E-mail: elicamboim@yahoo.com.br 